\title{
Long term predictors of adherence to Antiretroviral Therapy for HIV positive adults at Felege-Hiwot Teaching and Specialized Hospital, North-West Ethiopia: a transitional study
}

\author{
Awoke Seyoum Tegegne ${ }^{1, *}$, Principal Ndlovu ${ }^{2}$, Temesgen Zewotir ${ }^{3}$ \\ ${ }^{1}$ Department of Statistics, Bahir Dar University, Bahir Dar, Ethiopia, E-mail: \\ bisrategebrail@yahoo.com, cell phone: +251(0)918779451 \\ ${ }^{2}$ Department of Statistics, University of South Africa, Pretoria, South Africa, \\ E-mail: ndlovp@unisa.ac.za \\ ${ }^{3}$ School of Mathematics, Statistics and Computer Science, Kwazulu Natal \\ University, Kwazulu Natal, South Africa, E-mail: zewotir@ukzn.ac.za
}

\begin{abstract}
In clinical trials and practices, failure of adherence to medications is a common challenge among patients with chronic diseases. Many factors are associated with this failure. Reports of previous studies about predictors of adherence to Highly Active Antiretroviral Therapy (HAART) were not consistent. The main objective of this study was to identify predictors of long-term adherence to HAART, considering lag variables as additional predictors. Transitional modeling was used to determine the predictors of long-term adherence to HAART. A retrospective transitional study design was conducted on 792 randomly selected adult patients at Felege-Hiwot Teaching and Specialized Hospital, Bahir Dar, Ethiopia. Results revealed that the first two lag-variables $\left(Y_{i j-2}, Y_{i j-1}\right)$ were significantly associated with performance of current adherence to HAART. The increase in CD4 cell count change was significantly associated with current adherence, if patients made transition from adherent level at lag2 to non-adherent level at lag1 $\left(Y_{i j-2}=\right.$ $\left.1, Y_{i j-1}=0\right)$. As a conclusion, for patients who were transferred from adherent level at lag2 to non-adherent level at lag1, their CD4 cell count changes were positively correlated with current adherence level. Due attention should thus be given to address the specific needs of each group of patients. Non-adherence to HAART in this long-term treatment program was at risk and should receive interventional action. Educational therapy during follow-ups should also be given to non-adherent patients to strengthen the era of longterm treatment.
\end{abstract}

Keywords: Adherence, HAART, Longitudinal data, Transition model, Lag-variables, CD4 cell count change.

DOI: https://dx.doi.org/10.4314/ejst.v11i3.1

${ }^{*}$ Corresponding author: bisrategebrail@yahoo.com 


\section{INTRODUCTION}

Human immunodeficiency virus (HIV) gradually attacks the immune system, which is our body's natural defense against illness (Avert, 2016). AIDS is deadly infectious disease caused by HIV (Moore, 2011). It is the last stage of HIV infection where the body can no longer defend itself. HIV/AIDS infects people of all ages, sexes, races and income status, leading to poor health and socio-economic outcomes across the world (Moore, 2011).

Eastern and Southern Africa is the hardest region hit by the HIV as compared to countries in other parts of the world. Ethiopia is one of the few countries with the highest number of people living with HIV/AIDS. Amhara region is one of the regions significantly affected by the disease in the country (Seyoum and Zewotir, 2016). Felege Hiwot Hospital, Bahir Dar, Ethiopia, is a regional, teaching and specialized hospital with regional laboratory for HIV/AIDS related issues and incorporates all HIV/AIDS related data for each zonal and district hospitals in the region.

Assessment of predictors for adherence to Highly Active Antiretroviral Therapy (HAART) not only provides information related to low levels of adherence but also enables one to give attention to potential predictors in service provision to targeted patients. Moreover, the knowledge of target population about potential predictors for failure of adherence to HAART also helps to make interventions to enhance or maintain minimal services in the era of long term treatment for group members of HAART users (Sisay et al., 2018). Medication adherence is considered to be a complex behavior that is categorized under socio-demographic and patient-related activities (Sisay et al., 2018). Treatment adherence is known to affect the outcome, but adherence behavior differs not only between patients but also over time (McLain et al., 2015).

Different studies have been conducted related to predictors of adherence to HAART. A systematic review provided a comprehensive assessment of predictors/correlates of failure of adherence to HAART, but it did not aggregate findings into quantitative estimates of their effect on adherence 
(Anlay et al., 2016). A number of other studies focused only on patient reported barriers and facilitators, socio-demographic factors (Jamison et al., 2006), clinical and treatment-related factors (Atkinson and Petrozzino, 2009) as well as on patient related factors such as drug users (Connolly et al., 2011). Although the results of some of these studies appear to be conflicting, important information has emerged about the extent and factors associated with adherence (Adams and Luguterah, 2013a). The findings of these studies, however, lack consistency and fail to consider a series of the potential effect of lag-variables and their interaction with corresponding covariates.

In longitudinal studies, a series of individual responses could be reconsidered. Different models can be used to handle such dependence. One of the approaches appropriate for the primary question of interest is transition model (Chahkandi and Ganjali, 2009) where the effect of previous response is considered as an additional predictor for the current response. The model for current response, which relies on the previous response, might reduce the effects of some covariates that had previously been strongly significant (Adams and Luguterah, 2013b).

The introduction of Highly Active Antiretroviral Therapy (HAART) reduced morbidity and mortality rates of HIV infected patients (Seyoum and Temesgen, 2017). Numerous studies show that adherence to therapy slows down the progression of AIDS and death of patients (Seyoum and Temesgen, 2017). However, most studies show that the average rate of adherence to therapy is only $70 \%$ of the prescribed doses and could still be lower in some areas where active substance users are common (Seyoum et al., 2016). In the Amhara Region of Ethiopia including the catchment area of Felege Hiwot Teaching and Specialized Hospital, many ART users did not seriously adhere to their prescribed medication (Seyoum and Temesgen, 2017). Hence, for the majority of ART users at this hospital, adherence to HAART was lower than $95 \%$ of the prescribed medication and over $30 \%$ of the patients were poor adherents (Seyoum et al., 2017). This made the study area more appropriate for the current investigation. Moreover, the scarcity of researches and their inconsistency related to adherence to HAART in this area made this investigation vital. Therefore, the objective of this study was to identify 
long term predictors including lag-variables as additional explanatory variables for the adherence of patients to HAART.

\section{MATERIALS AND METHODS}

\section{Study design}

A retrospective cohort study design was conducted to assess predictors of adherence to HAART among adult HAART users enrolled from September to June 2008 and followed-up to June 2012. A transitional modeling was conducted to assess the effect of lag-variables and other predictors on adherence to HAART result.

\section{Inclusion criteria}

Adult patients, $15+$ years old, with a CD4 cell count below 200 cells $/ \mathrm{mm}^{3}$ or patients with World Health Organization (WHO) stage IV of HIV disease regardless of CD4 cell count, enrolled at Felege-Hiwot Teaching and Specialized Hospital, were included under this study. Patients with a minimum of 2 visits were also included in the study for this longitudinal data analysis.

\section{Sample size and sampling procedure}

A random sample of 792 patients was selected using stratified random sampling technique considering their residence area as stratum. In calculating the sample size, $95 \% \mathrm{CI}$ and 5\% margin of error were taken into account. Assuming that $10 \%$ of the selected sample cards of the patients to be considered as incomplete for inclusion criterion, the determined sample size was multiplied by 2 to consider the effect of the strata and to increase the power of precision (Seyoum et al., 2017). Moreover, attempts were made to compute the required sample size by employing two population proportion techniques. However, all were found below 792. Therefore, 792 were taken as the final sample size (Seyoum and Temesgen, 2017). 


\section{Data collection procedures}

In this study, only secondary data was used. Data extraction check-list was designed and used to extract the required secondary data. The baseline CD4 cell count and first month adherence was considered as covariate for the longitudinal study. Similarly, other information related to socio-demographic variables, number of visiting times and clinical data were also extracted from the records of each patient. The data was extracted by professional health care service providers after receiving adequate orientation about the variables to be included in the study.

\section{Quality of data}

The quality of the data was monitored by data controllers from ART section of the hospital. The controllers were trained by the Ministry of Health for their day to day activities related to data management of HIV patients. The data extraction tools and the variables included in the study were tested for consistency of understanding and completeness of the data items on 45 random samples. After that necessary amendments were made on the final data collection sheet.

\section{Variables included in the study}

The longitudinal response variable for the current study was adherence to HAART. A patient is said to be non-adherent if his/her adherence performance was lower than $95 \%$ of the prescribed medication and adherent if a patient's adherence performance was at least $95 \%$ of the prescribed medication. The trend of adherence to HAART was tested using Cochran-Armitage test. On the other hand, the predictor variables for the current study were age in years, sex (male, female), marital status (living with partner, living without partner), ownership of cell phone (yes, no), weight in kilogram, baseline CD4 cell count in cells $/ \mathrm{mm}^{3}$, disclosure of the disease to families (yes, no), residence area (rural, urban), WHO stages (stage I, stage II, stage III, stage IV), level of income (low, middle, high), number of visiting times $(1,2, \ldots, 23)$ and level of first month adherence to HAART (non-adherent, adherent). Additionally, 
lag-variables were also considered as additional predictors to the variable of interest.

\section{Impact of missing data on the analysis}

During this study, missing data steadily increased over time because of death, dropouts, or transfers to other health institutions (Seyoum and Zewotir, 2016). At the last follow up visit (23 ${ }^{\text {rd }}$ visit), about 74 (9.3\%) of the patients had dropped out from the treatment due to the above reasons. A logistic regression was conducted to assess whether or not missing values were affected by previous results and missing values were found independent of the previous outcomes $\left(\chi_{1}^{2}=0.6018, \mathrm{p}\right.$-value $\left.=0.584\right)$. Missing data were also found independent of predictor variables. Dropout patients did not have reasons attributable to their progression rate of their previous visits as well as predicators. Therefore, the trend of such missing values was noted as Missed Completely at Random (MCAR) (Seyoum and Temesgen, 2017; Tegegne and Zewotir, 2018a; Tegegne and Zewotir, 2018b).

\section{Data structure, compilation and analysis strategy}

Secondary data were entered and analyzed using SAS version 9.2 software. For the sample to be included in the study, CD4 cell count measurement just before the initiation of HAART was considered as a covariate so that there could be at least two visit responses after the initiation of HAART for the data to be analyzed. Categorical variables were summarized using frequencies and percentages while numerical variables were summarized using median and interquartile range (IQR). A Chi-square test of association was conducted to compare categorical baseline characteristics that were included in and excluded from the investigation. Independent samples t-test was used to compare the inclusion and exclusion of continuous predictor variables. Transition models (special kind of conditional models) were used for assessing factors affecting adherence to HAART over time with the inclusion of lag-variables and correlated data obtained from repeated measures. Considering a series of transition models using 'Proc Logistic' procedure of SAS, first, assessment was made on the dependence of the current 
response on the immediate previous result, $\mathrm{y}_{\mathrm{ij}-1}$ and thereafter, assessed the dependence of the current result on the two immediate previous results $\left(\mathrm{y}_{\mathrm{i}-1}, 1, \mathrm{y}_{\mathrm{i}-2}\right)$. The procedure continued to the responses for three occasions prior to the current one $\left(\mathrm{y}_{\mathrm{ij}-1}, \mathrm{y}_{\mathrm{ij}-2}, \mathrm{y}_{\mathrm{ij}-3}\right)$.

\section{Model description, assumption and adequacy}

In model selection procedure, all predictors in the model were considered, taking into account each product terms of predictor variables to be fitted one at a time. This was important to assess the interaction effects of predictors on the variable of interest. This indicates that missing values do not depend on values of response variable (Little and Rubin, 2014). Categorizing all patients into two (non-adherent or adherent), three models, namely, first-order, second-order and third-order models were fitted, where the previous responses were considered as additional explanatory variables. Appropriateness of link function for the adherence to HAART data was tested among the two predictors, namely, linear and quadratic. Among the two, linear predictors were significant for the variable of interest and considered as the appropriate link function for prediction of the dependent variable (Noorian and Ganjali, 2012). The sensitivity of inference about coefficients of regression to second order Markov assumptions was assessed by considering the similarity between standard errors for model based and empirical results. This assignment was conducted using generalized linear mixed model, and the results obtained in this procedure showed that standard errors resulted from the model based and empirical results were approximately similar, which witnessed the validity of second order Markov assumptions.

\section{Research ethics approval}

Ethics approval certificate had been obtained from two universities:

Bahir Dar University, Ethiopia (Ref $\neq$ RCS/1412/2006) and University of South Africa (UNISA), (Ref $\neq: 2015$ - SSR - ERC - 006). 


\section{RESULTS AND DISCUSSION}

All included and excluded sample units in this cohort had almost the same baseline characteristics. Applying independent samples t-test for quantitative variables and proportion for categorical variables, the average weight of the included sample was $57.5 \mathrm{~kg}$ and those excluded was $59 \mathrm{~kg}$ with p-value of 0.78 . Included male patients were $54.5 \%$ and excluded ones $53 \%$, with p-value of 0.73 . Baseline characteristics of patients are summarized in Table 1.

The median age of the sample was 36 years (IQR: 28-48) (Table 1). Some $50.6 \%$ of the patients included in the study were females; $40.9 \%$ resided in rural areas; $55.2 \%$ had no partners; $27.4 \%$ of the total sample had disclosed that they are infected to family members living together, and $68.3 \%$ adhered to the medication scheme. Over $50 \%$ of the patients had attended secondary education and about one-half of them used their cell phones as memory aid. The probability of adherence to the prescribed medication increased from first visit to the last visit of the study period. The increasing rate of adherence to HAART was tested using CochranArmitage statistics, which gave a strong evidence $(Z=18.25$, $p$-value $<$ 0.0001 ) that adherence to HAART did in fact increase over time (Agresti and Kateri, 2011).

To assess the level of significance of the previous results on the current outcome, type 3 analyses (used to identify whether the given variable at $25 \%$ were significant or not) were conducted. The assessment was also made on predictors including effects of previous result/outcome on the current adherence to HAART (Table 2).

The results in Table 2 indicate that the variable of interest very strongly depended on lag1, $\mathrm{y}_{\mathrm{ji}-1}(\mathrm{p}$-value $=0.0048)$. Similarly, the current result also highly depended on lag2, $\mathrm{y}_{\mathrm{ij}-2}(\mathrm{p}$-value $=0.0320)$. However, the variable of interest was independent of lag3, $y_{i j-3}(p$-value $=0.2213)$, and therefore, considering lag3 and lags before it for further analysis was unnecessary (Seyoum et al., 2017). 
Table 1. Baseline socio-demographic and clinical characteristics of sampled patients $(\mathrm{n}=792)$

Variables Levels $\quad$ Observed

Quantitative variables

Weight $(\mathrm{kg})$

Baseline CD4 cell count

Age (years)

$1^{\text {st }}$ Month average CD4 count change

Qualitative variables

Sex

Level of education.

Residence area

Marital status (living with)

Level of income

WHO stages

Ownership of cell phone

First month HAART adherence
Disclosed disease to families

\section{Levels}

\begin{tabular}{|c|c|}
\hline & 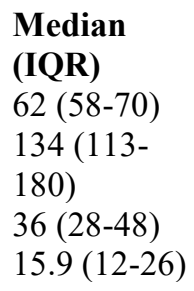 \\
\hline & $\mathbf{N}(\%)$ \\
\hline Male & $391(49.4)$ \\
\hline Female & $401(50.6)$ \\
\hline No education & $160(20.2)$ \\
\hline Primary & $205(25.9)$ \\
\hline Secondary & $273(34.5)$ \\
\hline Tertiary & $154(19.4)$ \\
\hline Urban & $468(59.1)$ \\
\hline Rural & $324(40.9)$ \\
\hline Partner & $355(44.8)$ \\
\hline No partner & $437(55.2)$ \\
\hline Low $(<500)^{\mathrm{a}}$ & $355(44.8)$ \\
\hline Middle (5001-999) & $346(43.7)$ \\
\hline $\operatorname{High}(\geq 1000)$ & $91(11.5)$ \\
\hline Stage I & $101(12.8)$ \\
\hline Stage II & $258(32.6)$ \\
\hline Stage III & $199(25.1)$ \\
\hline Stage IV & $234(29.5)$ \\
\hline Yes & $575(72.6)$ \\
\hline No & $217(27.4)$ \\
\hline Yes & $400(50.5)$ \\
\hline No & $392(49.5)$ \\
\hline Adherent & $540(68.2)$ \\
\hline Non- adherent & $252(31.8)$ \\
\hline
\end{tabular}

${ }^{a}$ Low ( $\left.<500\right)$ stands for Low income $(<500 \mathrm{ETB} /$ month), Middle (5001-999) for Middle income (5001-999 ETB/month) and High $(\geq 1000)$ for High income ( $\geq 1000 \mathrm{ETB} / \mathrm{month})$. 
An assessment was then conducted to identify whether any interaction terms (between the previous response and explanatory variables) need to be incorporated for further analysis. To examine this, the second-order model (Table 2) was extended by fitting each of the two-way interaction terms formed from the previous responses and explanatory variables. These variables, whose significances were assessed, were added to the model, one at a time. Four interactions reduced the deviance by relatively large amounts: 1) lag1*time of follow-up visits led to a deviance reduction of 528 with a corresponding p-value of 0.001 ; 2) lag2 $*$ first month adherence reduced the magnitude of deviance of 478 with corresponding p-value of $0.002 ; 3)$ lag2 $*$ CD4 cell count change with deviance reduction of 4.34 and corresponding p-value of 0.003 ; and 4) lag2 * owner of cell phone reduced the deviance by 3.98 and p-value of 0.025. All the four interactions were fitted at the same time to assess whether or not their interactions be included in the model. And they reduced the deviance by 17.82 and a corresponding p-value of 0.002 . The goodness-of-fit was tested using Hosmer-Lemoshow test (goodness-offit statistic $=8.249, \mathrm{p}$-value $=0.241$ ). This shows the model was good $(\mathrm{p}>0.05)$. Therefore, the final transition model with second order was selected. Using linear link function and second order Markov assumptions, regression coefficients and standard errors were estimated (Table 3). The parameter estimates and the corresponding confidence limits for Markov chain of orders 2 are also shown (Table 3).

Other variables kept constant, with a unit increase in number of visiting times, the odds of adherence was $1.5 \%$ less likely for patients who were adherent in the previous two results $\left(y_{i j-2}=1\right.$ and $\left.y_{i j-1}=1\right)$ (Table 3). On the other hand, the odds of adherence were 0.585 times less likely for those patients who were non-adherent at lag2 $\left(y_{i j-2}=0\right)$ but adherent at lag1 $\left(y_{i j-1}=1\right)$ when compared to those patients who were non-adherent at lag2 and lag1 $\left(y_{i j-2}=0\right.$ and $\left.y_{i j-1}=0\right)$. 
Table 2. Type 3 analyses of effects of first, second and third order models for adherence to HAART data

\begin{tabular}{|c|c|c|c|c|c|c|c|}
\hline \multirow[b]{2}{*}{ Effects } & \multirow[b]{2}{*}{$\mathbf{D F}^{\mathbf{a}}$} & \multicolumn{2}{|c|}{ First order } & \multicolumn{2}{|c|}{ Second order } & \multicolumn{2}{|c|}{ Third order } \\
\hline & & Wald $\chi^{2}$ & p-value & Wald $\chi^{2}$ & p-value & Wald $\chi^{2}$ & p-value \\
\hline$\overline{\text { Age }}$ & 1 & 1.63 & 0.019 & 1.35 & 0.020 & 1.160 & 0.020 \\
\hline Weight & 1 & 11.83 & 0.015 & 11.02 & 0.023 & 10.821 & 0.045 \\
\hline Initial CD4 & 1 & 9.26 & 0.0274 & 8.65 & 0.040 & 7.952 & 0.042 \\
\hline Area & 1 & 8.89 & 0.038 & 8.32 & 0.040 & 6.722 & 0.460 \\
\hline Education & 3 & 7.62 & 0.028 & 6.93 & 0.036 & 5.732 & 0.045 \\
\hline Marital status & 1 & 9.24 & 0.014 & 8.72 & 0.024 & 7.861 & 0.030 \\
\hline Sex & 1 & 5.06 & 0.013 & 4.35 & 0.033 & 3.431 & 0.050 \\
\hline Household income & 2 & 5.23 & 0.039 & 4.18 & 0.050 & 3.97 & 0.060 \\
\hline Owner of phone & 1 & 4.18 & 0.016 & 3.63 & 0.030 & 3.16 & 0.040 \\
\hline CD4 cell count change & 1 & 5.23 & 0.013 & 5.12 & 0.029 & 4.63 & 0.035 \\
\hline First month adherence & 1 & 24.48 & 0.011 & 21.32 & 0.021 & 18.16 & 0.040 \\
\hline Disease exposedness & 1 & 4.93 & 0.037 & 4.24 & 0.047 & 3.89 & 0.048 \\
\hline WHO stages & 3 & 2.68 & 0.034 & 2.17 & 0.184 & 1.95 & 0.300 \\
\hline Time (Visiting times) & 1 & 11.86 & $<0.001$ & 10.17 & 0.004 & 9.95 & 0.005 \\
\hline Time *area & 1 & 4.49 & 0.022 & 3.35 & 0.041 & 2.67 & 0.060 \\
\hline Time $*$ marital status & 1 & 2.12 & 0.041 & 1.71 & 0.046 & 0.98 & 0.048 \\
\hline Time*disease exposed & 1 & 4.33 & 0.042 & 4.16 & 0.039 & 3.41 & 0.023 \\
\hline Time $*$ education & 3 & 12.28 & $<.001$ & 11.26 & 0.018 & 10.24 & 0.030 \\
\hline Age $*_{\text {initial adherence }}$ & 1 & 18.81 & $<.000$ & 18.65 & 0.036 & 17.27 & 0.046 \\
\hline
\end{tabular}




\begin{tabular}{|c|c|c|c|c|c|c|c|}
\hline Age *area & 1 & 7.27 & 0.160 & 7.03 & 0.270 & 6.81 & 0.297 \\
\hline Age*sex & 1 & 5.63 & 0.022 & 4.32 & 0.022 & 3.96 & 0.024 \\
\hline $\operatorname{Lag} 1\left(y_{\mathrm{ij}-1}\right)$ & 1 & 10.39 & 0.004 & 9.43 & 0.006 & 8.29 & 0.005 \\
\hline $\operatorname{Lag} 2\left(y_{\mathrm{ij}-2}\right)$ & 1 & & & 11.41 & 0.030 & 11.29 & 0.032 \\
\hline $\operatorname{Lag} 3\left(y_{i j-3}\right)$ & 1 & & & & & 5.18 & 0.221 \\
\hline
\end{tabular}

Table 3. Second-order Markov chain empirical parametric estimation with standard errors for adherence to HAART data using transition model

\begin{tabular}{llrllllrr}
\hline Effect & Levels & Estimate & SE & AOR & AOR CL & \multicolumn{1}{c}{$\begin{array}{c}\text { Wald } \\
\text { statistic }\end{array}$} & p-value \\
\hline Intercept & & -0.19 & 0.049 & 0.824 & 0.621 & 0.995 & -81.81 & $<.000$ \\
Age & & -1.20 & 0.001 & 0.301 & 0.198 & 0.699 & -0.84 & 0.001 \\
Weight & 0.03 & 0.000 & 1.036 & 0.999 & 1.061 & 0.92 & 0.357 \\
Baseline CD4 cell count & & -2.01 & 0.000 & 0.134 & 0.099 & 0.300 & -2.54 & 0.011 \\
CD4 cell count change & & 0.81 & 0.032 & 2.248 & 1.702 & 3.466 & 0.36 & 0.021 \\
Visiting time & & 0.09 & 0.001 & 1.094 & 1.016 & 2.418 & 14.06 & $<.000$ \\
Residence (Ref.= urban) & Rural & -3.07 & 0.003 & 0.046 & 0.009 & 0.499 & -0.25 & 0.000 \\
Marital status (Ref.=with partner) & Without partner & -4.51 & 0.019 & 0.011 & 0.004 & 0.686 & -2.69 & 0.007 \\
Education (Ref.= tertiary) & Secondary & -2.81 & 0.028 & 0.060 & 0.022 & 0.274 & -2.89 & 0.004 \\
& Primary & -3.05 & 0.027 & 0.047 & 0.011 & 1.003 & -1.86 & 0.063 \\
& No education & -4.01 & 0.030 & 0.018 & 0.009 & 0.321 & -4.73 & $<.000$ \\
Sex (Ref.= female) & Male & -3.02 & 0.015 & 0.049 & 0.018 & 1.098 & -0.22 & 0.059
\end{tabular}




\begin{tabular}{|c|c|c|c|c|c|c|c|c|}
\hline Cell phone (Ref.=yes) & No & -4.02 & 0.008 & 0.018 & 0.009 & 0.076 & -0.88 & 0.033 \\
\hline $\begin{array}{l}\text { First month adherence (Ref.= } \\
\text { adherent) }\end{array}$ & Non- adherent & -3.01 & 0.040 & 0.049 & 0.019 & 0.083 & -0.45 & 0.005 \\
\hline Disclosure of disease (Ref.= yes) & No & -1.01 & 0.010 & 0.364 & 0.170 & 1.010 & 0.97 & 0.325 \\
\hline Lag1 (ref.=no) & Yes & 0.04 & 0.005 & 1.041 & 1.011 & 1.061 & 7.83 & $<.000$ \\
\hline Lag2 (ref.=no) & Yes & -2.04 & 0.009 & 0.130 & 0.137 & 0.670 & -5.41 & $<.000$ \\
\hline $\begin{array}{l}\text { Time*marital status (Ref.=with } \\
\text { partner) }\end{array}$ & Without partner & -4.05 & 0.000 & 0.017 & 0.009 & 1.001 & -4.18 & 0.051 \\
\hline $\begin{array}{l}\text { Time*residence area } \\
\text { (Ref.=urban) }\end{array}$ & Rural & -3.02 & 0.000 & 0.048 & 0.016 & 0.098 & -12.77 & 0.000 \\
\hline $\begin{array}{l}\text { Time*disease disclosure } \\
\text { (Ref.=yes) }\end{array}$ & No & -1.8 & 0.000 & 0.165 & 0.081 & 0.424 & -4.30 & $<0.000$ \\
\hline Time*cell phone $($ Ref. $=y e s)$ & No & -0.092 & 0.000 & 0.912 & 0.639 & 0.999 & -2.32 & $<0.000$ \\
\hline Time*sex $($ Ref. $=$ female $)$ & Male & -3.39 & 0.091 & 0.034 & 0.018 & 0.199 & -7.22 & 0.007 \\
\hline $\begin{array}{l}\text { Lag } 2 * \text { first month adherence } \\
(\text { Ref. }=\text { no) }\end{array}$ & Yes & -4.21 & 0.000 & 0.015 & 0.007 & 0.199 & -1.50 & 0.018 \\
\hline Lag $1 *_{\text {visiting time }(\text { Ref. }=\text { no })}$ & Yes & -4.59 & 0.039 & 0.010 & 0.008 & 0.058 & -7.58 & $<.000$ \\
\hline Age*residence (Ref,=urban) & Rural & 0.06 & 0.072 & 1.062 & 1.028 & 1.199 & 6.83 & $<.000$ \\
\hline $\begin{array}{l}\mathrm{Lag} 2 * \mathrm{CD} 4 \text { cell count change } \\
\text { (Ref.= no) }\end{array}$ & Yes & 0.23 & 0.000 & 1.259 & 1.093 & 1.534 & 0.45 & 0.036 \\
\hline Lag2 $*$ cell phone $($ Ref. $=$ no $)$ & Yes & 0.36 & 0.000 & 1.433 & 1.101 & 1.708 & 0.68 & 0.009 \\
\hline
\end{tabular}

Ref stands for reference, AOR for Adjusted odds ratio, AOR 95\% CL for 95\% AOR confidence limit, SE for standard error. 
This indicates that the rate of increase in adherence level was significantly higher for patients who were none-adherent at two visits prior to the current observation $\left(y_{i j-2}=0\right.$ and $\left.y_{i j-1}=0\right)$ than those who were non-adherent at lag2 $\left(y_{i j-2}=0\right)$ and then being adherent at lag1 $\left(y_{i j-1}=1\right)$ in the two successive visits. Small p-values indicate significance (Table 3 ). The interaction effect indicates that the rate of increase in adherence performance was significantly higher for patients who were non-adherent at the first and second lag-variables $\left(y_{i j-2}=0\right.$ and $\left.y_{i j-1}=0\right)$ when compared to those patients who were non-adherent at lag2 but adherent at lag1 $\left(y_{i j-2}=0\right.$ but $\left.y_{i j-1}=1\right)$ (Figure 1). The other significant interaction effect depicted in Table 3 was lag $2 *$ ownership of cell phone with adjusted odds ratio and corresponding 95\% confidence limits $(\mathrm{AOR}=1.4333,95 \% \mathrm{CL}:(1.1013,1.7084)$, $\mathrm{p}$-value $=0.0089)$. The result indicates that patients who possessed cell phone were $43 \%$ more likely to be adherent to HAART at current visit than patients without cell phone, given the condition that such patients were transferred from adherent level at lag2 to non-adherent level at lag1 follow up visits $\left(y_{i j-2}=1\right.$ and $\left.y_{i j-1}=0\right)$. There was no significant difference in adherence performance between patients with or without cell phone provided that such patients were non-adherent level at both lag2 and lag1 $\left(y_{i j-2}=0\right.$ and $\left.y_{i j-1}=0\right)$. Similarly, there was no statistically significant difference between adherence to HAART for patients with cell phone or without cell phone if such patients were transferred from non-adherent level at lag2 to adherent level at lag1 follow up visits $\left(y_{i j-2}=0\right.$ but $y_{i j-1}=1$ ) (Table 4). The current adherence to HAART was 2.15 times more likely for patients who were adherent to HAART at the first month given that such patients made transition from adherent level at lag2 to non-adherent level at lag1 follow up visits as compared to patients who made a transition from non-adherent level at lag2 to non-adherent level at lag1 $\left(\mathrm{y}_{\mathrm{ij}-2}=1\right.$ and $\left.\mathrm{y}_{\mathrm{ij}-1}=0\right)$ versus $\left(\mathrm{y}_{\mathrm{ij}-2}=0\right.$ and $\left.\mathrm{y}_{\mathrm{ij}-1}=0\right)($ Table 4$)$. 


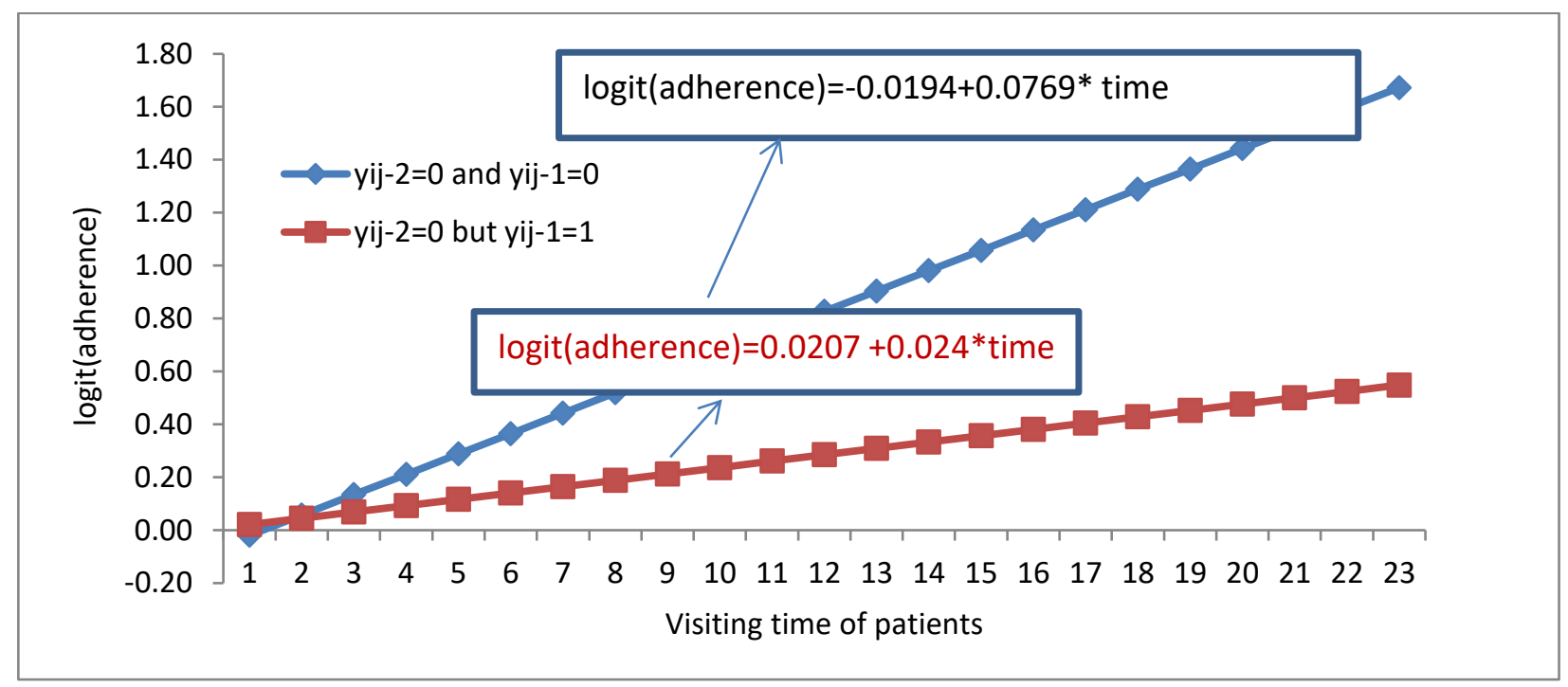

Figure 1. Log odds of adherence of the interaction effect between visiting time and previous results 
Table 4. Interaction effects between outcomes at previous visits with some covariates

\begin{tabular}{|c|c|c|c|c|}
\hline \multirow{2}{*}{\multicolumn{2}{|c|}{$\begin{array}{l}\text { Contrast } \\
\text { With cell phone vs. without }\end{array}$}} & \multirow[t]{2}{*}{$\begin{array}{l}\text { Adjusted odds } \\
\text { ratio (AOR) }\end{array}$} & \multicolumn{2}{|c|}{$\begin{array}{l}95 \% \text { CI for odds } \\
\text { ratio }\end{array}$} \\
\hline & & & & \\
\hline $\mathrm{y}_{\mathrm{ij}-2}=0$ and $\left.\mathrm{y}_{\mathrm{ij}-1}=0\right)$ & -0.006 & 0.7564 & 0.5672 & 1.0862 \\
\hline $\mathrm{y}_{\mathrm{ij}-2}=1$ and $\left.\mathrm{y}_{\mathrm{ij}-1}=0\right)$ & 0.0351 & 1.0357 & 1.0186 & $1.4891^{*}$ \\
\hline \multicolumn{5}{|c|}{$\left(y_{i j-2}=0\right.$ and $\left.y_{i j-1}=0\right)$ versus $\left(y_{i j-2}=1\right.$ and $\left.y_{i j-1}=0\right)$} \\
\hline $\begin{array}{l}\text { Patients with cell } \\
\text { phone }\end{array}$ & 0.0635 & 1.0656 & 1.0084 & $1.5976^{*}$ \\
\hline $\begin{array}{l}\text { Patients without cell } \\
\text { phone }\end{array}$ & -0.0054 & 0.9946 & 0.5832 & 1.2504 \\
\hline \multicolumn{5}{|c|}{ Adherent versus non- adherent at first month } \\
\hline $\mathrm{y}_{\mathrm{ij}-2}=0$ and $\left.\mathrm{y}_{\mathrm{ij}-1}=0\right)$ & -0.0084 & 0.9916 & 0.2672 & $0.9999^{*}$ \\
\hline $\mathrm{y}_{\mathrm{ij}-2}=1$ and $\left.\mathrm{y}_{\mathrm{ij}-1}=0\right)$ & -0.0252 & 0.9751 & 0.8472 & 1.1662 \\
\hline \multicolumn{5}{|c|}{$\left(y_{i j-2}=0\right.$ and $\left.y_{i j-1}=0\right)$ versus $\left(y_{i j-2}=1\right.$ and $\left.y_{i j-1}=0\right)$} \\
\hline $\begin{array}{l}\text { Adherent at first month } \\
\text { result }\end{array}$ & 0.7653 & 2.1542 & 1.8098 & $2.5273^{*}$ \\
\hline $\begin{array}{l}\text { Non-adherent at first } \\
\text { month result }\end{array}$ & -0.0652 & 0.9368 & 0.5721 & 1.2862 \\
\hline \multicolumn{5}{|c|}{$\begin{array}{l}\text { Extra CD4 cell count vs. no extra CD4 cell count }(\text { Ref. }=\text { Extra CD4 cell } \\
\text { count or positive change) }\end{array}$} \\
\hline $\mathrm{y}_{\mathrm{ij}-2}=1$ and $\left.\mathrm{y}_{\mathrm{ij}-1}=0\right)$ & 0.4211 & 1.5234 & 1.4851 & $1.5642^{*}$ \\
\hline $\mathrm{y}_{\mathrm{ij}-2}=0$ and $\left.\mathrm{y}_{\mathrm{ij}-1}=0\right)$ & -0.0070 & 0.9930 & 0.8225 & 1.1986 \\
\hline \multicolumn{5}{|c|}{$\left(y_{i j-2}=1\right.$ and $\left.y_{i j-1}=0\right)$ versus $\left(y_{i j-2}=0\right.$ and $\left.y_{i j-1}=0\right)$} \\
\hline $\begin{array}{l}\text { Patients with increased } \\
\text { CD4 cell count }\end{array}$ & 0.0635 & 1.4556 & 1.0942 & $1.6435^{*}$ \\
\hline $\begin{array}{l}\text { Patients without extra } \\
\text { CD4 cell count change }\end{array}$ & -0.0034 & 0.9966 & 0.9352 & 1.0356 \\
\hline
\end{tabular}

*indicates significant at $95 \%$ confidence interval, Ref stands for reference.

Patients who were adherent during the first month assessment were less likely to be adherent to HAART as compared to patients who were nonadherent during first month adherence provided that such patients were 
non-adherent at both lag2 and $\operatorname{lag} 1\left(y_{i j-2}=0\right.$ and $\left.y_{i j-1}=0\right)$ (AOR $=0.9916,95 \%$ CI: $(0.2672,0.9998)$.

The odds ratio and $95 \%$ confidence limit for interaction effects between previous adherence to HAART results and CD4 cell count change are shown in Table 4. Patients who had current extra CD4 cell count change $(\mathrm{AOR}=1.5234,95 \%$ CL: $(1.4851,1.5642)$ were $52 \%$ more likely to be adherent to medication than for patients with no extra CD4 cell count change provided that such patients were adherent at lag2 and were nonadherent at $\operatorname{lag} 1\left(\mathrm{y}_{\mathrm{ij}-2}=1\right.$ and $\left.\mathrm{y}_{\mathrm{ij}-1}=0\right)($ Table 4$)$. However, there was no significant difference between those patients who were adherent at lag2 but non-adherent to medication at lag1 and for those patients who were non-adherent level at both lag2 and lag1 visiting times with irrespective of the change of CD4 cell count (Table4). The contrasts were derived from the estimated model coefficients. The data in Table 4 indicates that regarding patients with high CD4 cell count change, the odds of adherence was $46 \%$ more likely to patients who made transition from adherent level at lag2 to non- adherent level at $\operatorname{lag} 1\left(\mathrm{y}_{\mathrm{ij}-2}=1\right.$ and $\left.\mathrm{y}_{\mathrm{ij}-1}=0\right)(95 \% \mathrm{CI}$ : $1.0942,1.6435)$. However, the change of CD4 cell count did not affect patients' adherence to HAART, if such patients made transition from nonadherent level at lag2 to lag1 $\left(\mathrm{y}_{\mathrm{ij}-2}=0\right.$ and $\left.\mathrm{y}_{\mathrm{ij}-1}=0\right)$.

Table 3 also shows other main and interaction effects without the involvement of previous results. Main effects like age, baseline CD4 cell count, CD4 cell count change, visiting times of patients, residence area, marital status, sex of patients, ownership of cell phone and first month adherence had significantly associated with the improvement of current adherence to HAART. The significance of these interactions depicted in Table 3 was demonstrated using the following figures.

Interaction effect between visiting time and residence area. As visiting time of a patient increased, adherence for patients in rural area were $99.3 \%$ less likely to be adherent for the prescribed medication than those who lived in urban area $(\mathrm{AOR}=0.0066,95 \% \mathrm{CI}:(0.0027,0.0099)$ and $\mathrm{p}$-value $=0.004)$. As visiting time increased, adherence to medication for both patients in urban and rural areas also increased but with different 
rates of increase (Figure 2). As visiting time increased, compared to rural patients, urban patients were more likely to be adherent.

Interaction effects between visiting times and disease disclosure to family members. It is known that as visiting time of patients increased, majority of patients were more likely to be more adherent (Table 3). But the levels of being adherent for those patients who disclosed the disease and did not disclose the diseases were different. Hence, as visiting time increased by one unit, patients who did not disclose the disease were $16.5 \%$ less likely to be adherent when compared to those patients who disclosed the disease $(\mathrm{AOR}=0.1653,95 \% \mathrm{CI}$ : $(0.0805,0.4235)$, p-value $<0.001$. As follow-up time of a patient increased, patients who disclosed their illness were more likely to be adherent when compared to those patients who did not disclose the disease (Figure 3).

Interactional effects between number of visiting times and possession of cell phone. As number of visiting times increased by one unit, patients with no cell phone were $8.9 \%$ times less likely to adhere when compared to patients with cell phone $(\mathrm{AOR}=0.9121,95 \% \mathrm{CL}$ $(0.6387,0.9987)$ and $p$-value $<0.00001)$ (Table 3, Figure 4).

Interactional effects between age and residence area of patients. As the age of patients increased, they were less likely to be adherent. The probability of decreasing their level of adherence was not the same for patients who lived in rural and urban areas. As age increased by one year, the decreasing rate of adherence for rural patients were $6.2 \%$ times more likely as compared to urban patients $(\mathrm{AOR}=1.0618,95 \% \mathrm{CL}$ (1.0275, $1.1993)$, p-value $<0.0001)$. Figure 5 indicates that as age of patients increased, the rate of reduction of adherence level was more rapid for patients who lived in the rural areas than in urban areas. Consistent with the results from the recent longitudinal studies, the findings in this study showed that adherence to HAART progression improved through time (Luguterah and Adams, 2013). This indicates that the interventions on program might have had a positive effect on patients' adherence to HAART. 


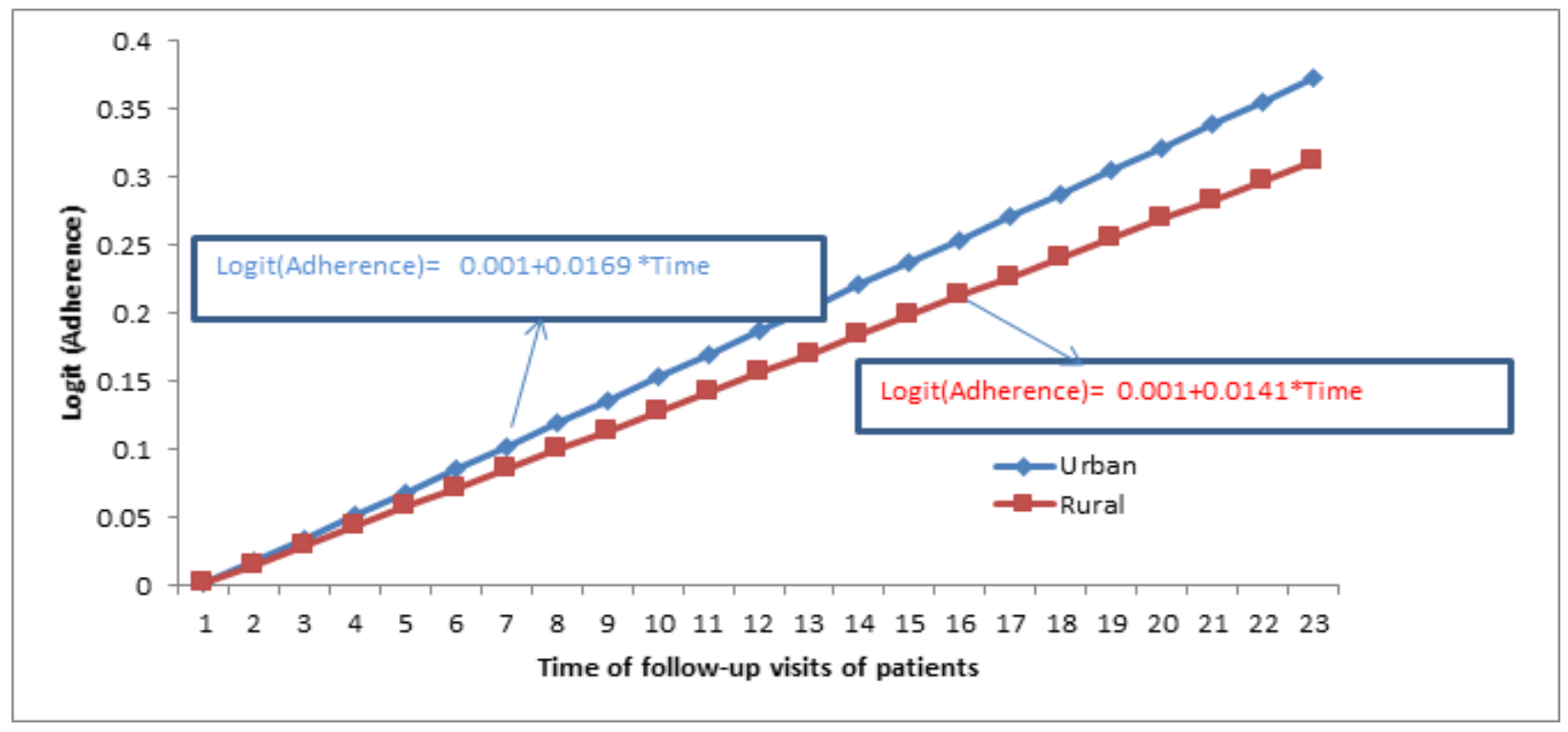

Figure 2. Plot of the interaction effect between visiting time and residence area of patients 


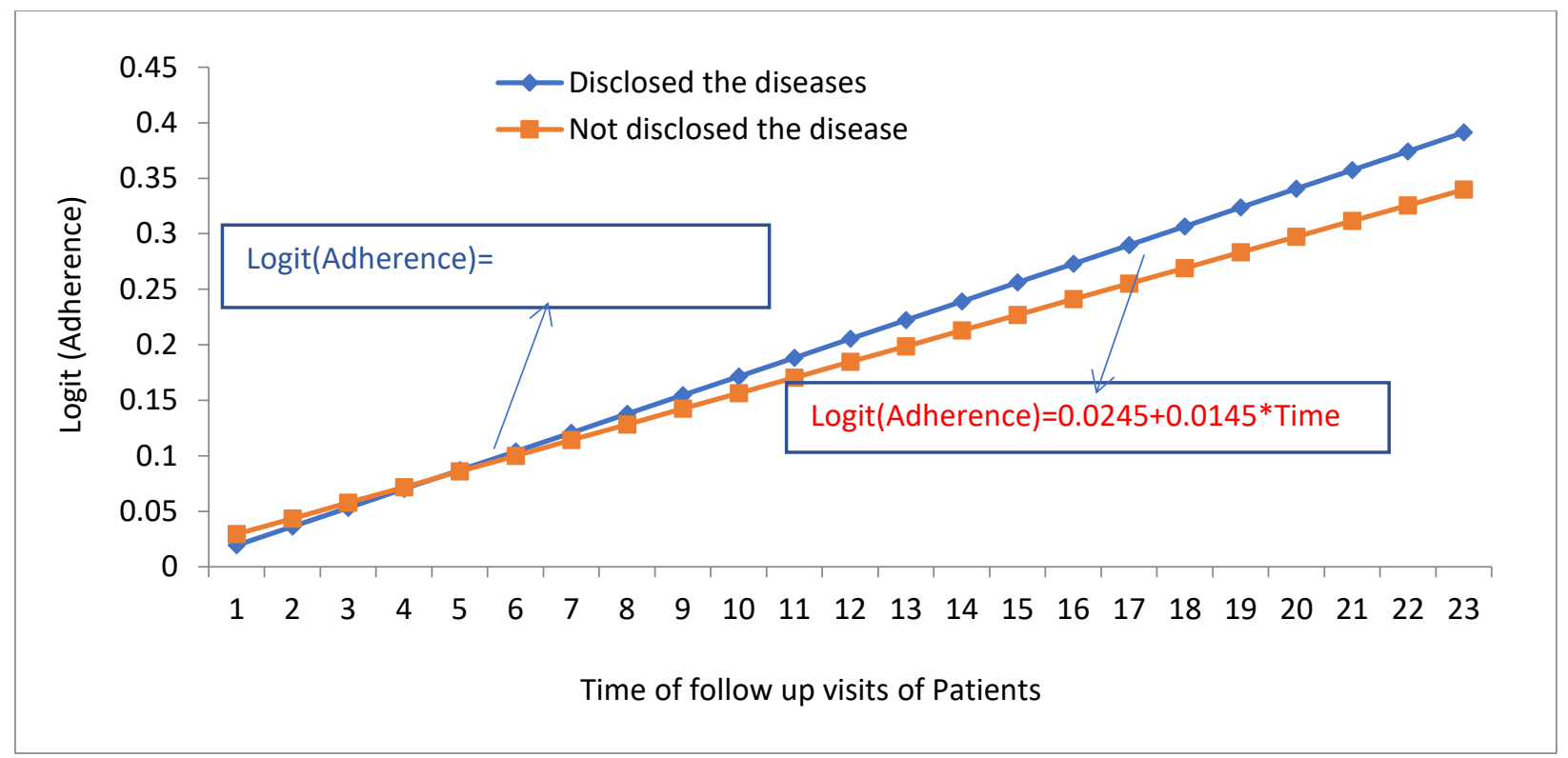

Figure 3. Plot of interaction effects between time and disease disclosure to family members 


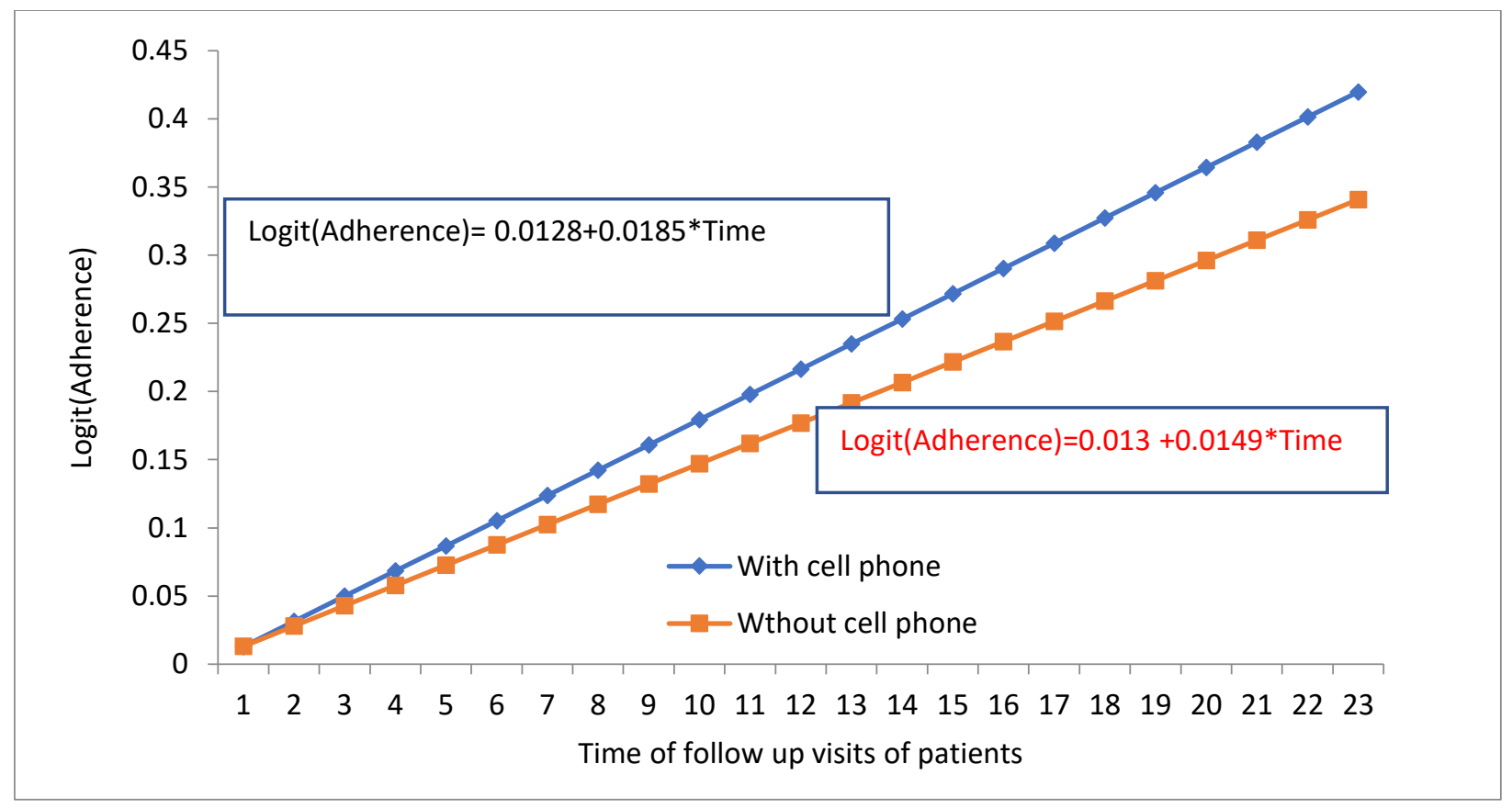

Figure 4. Plot of interactional effect between number of visiting time and possession of cell phone 
Both male and female patients had similar level of adherence to HAART at initiation of HAART; however, as the number of visiting time of patients increased, female patients' level of adherence to HAART became higher than their male counterpart. This disparity might have been because of females' good experience on adherence of pills to birth control, and this experience might have been transferred to their good performance of adherence to HAART (Asfaw et al., 2015b). Hence, it is possible to assume that women have been more responsible for caregiving duties and for adopting the behavior of taking pills at all times (Skhosana et al., 2006). This high HAART adherence behavior has made females to become better and healthy looking.

Recent studies have consistently indicated that a demographic characteristic such as age has significant association with the adherence to HAART (Adams and Luguterah, 2013a). Hence, as the age of a patient increased, the adherence to HAART decreased. This study also indicated that treatment was less effective for old age patients when compared to youngsters. This result confirmed the evidence from the literature that states immune function decreases with an increase of age.

The importance of early diagnosis to initiate adherence to HAART was indicated under this study. Patients who started HAART adherence with high baseline CD4 cell count had better current adherence result when compared to those patients initiated with low baseline CD4 cell count. This result agrees with the findings obtained from literature (Ehret et al., 2011) and contradicts with other findings (Montarroyos et al., 2014).

Patients living with partners had better adherence to HAART when compared to those living without partners. This might be due to the mutual support of partners; for instance, one could be reminded by his/her partner to take the prescribed medication or to visit hospitals on time. This result contradicts with the findings of other studies (Adams and Luguterah, 2013a) but is supported by others (Asfaw et al., 2015b). 


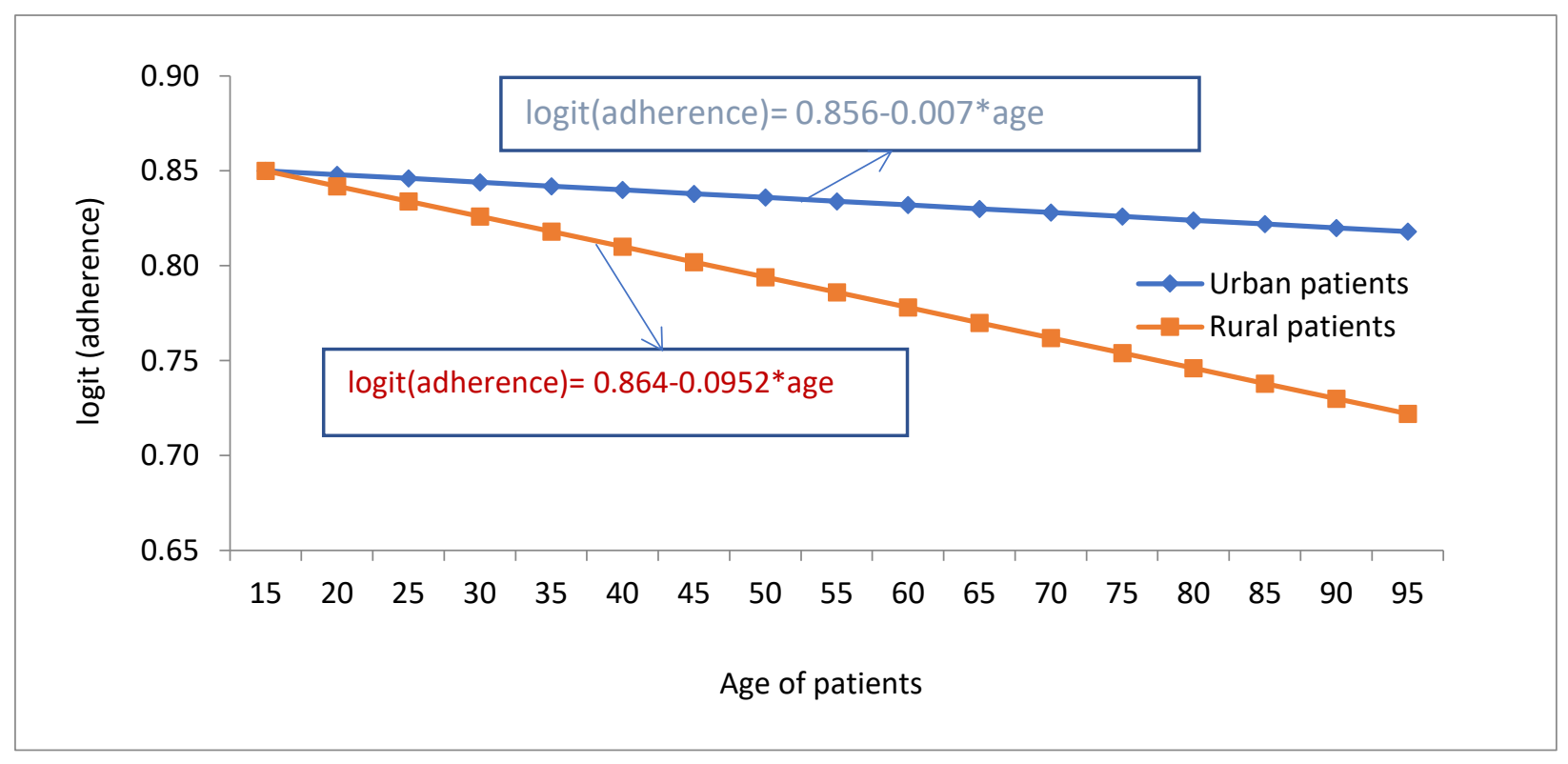

Figure 5. Plot of interactional effect between age and residence area of patients. 
CD4 cell count progression significantly affected patient adherence to HAART. Patients with better progress of CD4 cell count adhered better than patients whose CD4 cell count did not increase. This result is supported by a previous studies (e.g. Asfaw et al., 2015a), in which positive correlation between CD4 cell count change and adherence to HAART was reported.

Patients who owned cell phone adhered to prescriptions better than those without cell phone. Cell phones may serve as memory aid to remember the time to take pills (Maqutu et al., 2011). The results of the current findings were consistent with previous reports (Seyoum and Temesgen, 2017).

Urban patients adhered to HAART better than rural patients. Reasons for the difference might include that rural patients visited the hospital late for HIV diagnosis after significant reduction of CD4 cell count, a situation that was disappointing, forcing them to lose hope and eventually ignore HAART. Also, rural patients might not have regular access to checkup or HIV diagnosis. This means most of them were likely to come to hospital after they were seriously ill. The role of residence (urban and rural) in connection with adherence agreed with previous research reports (Adams and Luguterah, 2013a). Regarding lag-variables, the current adherence to HAART was dependent on the results of the two previous lag variables $\left(y_{i j-2}, y_{i j-1}\right)$. Hence, the significant effect of explanatory variables on the variable of interest was affected because of the previous results or lag-variables. In this study, the effect of CD4 cell count change on adherence to HAART was conditional. Thus, CD4 cell count change had its influence on adherence to HAART if a patient made transition from adherent to medication at lag2 to non-adherent for medication at lag1 $\left(y_{i j-2}=1\right.$ and $\left.y_{i j-1}=0\right)$. However, CD4 cell count had no influence for the current adherence to medication if a patient had nonadherent result at both lag2 and lag1 $\left(y_{i j-2}=0 \& y_{i j-1}=0\right)$. 


\section{CONCLUSION}

The results of this study indicated that some covariates including the two lag-variables were significantly associated with the level of adherence to HAART. The study also indicated that the response variable, adherence to HAART, increased on average through time. However, the rate of increase for different groups varied depending on residential area, sex, level of education, ownership of cell phone, disclosure of the disease and marital status. In addition, the current adherence to HAART result is different based on the results obtained from the transition periods (the recent two lag variables). The analysis in the current investigation identified a certain group of patients such as males and rural residents, who had a relatively maximum risk of treatment response. The response variable, adherence to HAART, was analyzed by considering the previous results as additional predictor variable, and the first and the second lag-variables $\left(y_{i j-2}, y_{i j-1}\right)$ were significant for the variation of the current adherence to HAART. In this study, transitional analyses of the effect of lag variables on current adherence to HAART data revealed that the previous response reduced the effect of CD4 cell count change on current adherence. The shorter the time it took from previous results to be adherent, the more likely for the effect to be on the current response variable.

\section{Limitations of study}

One of the limitations of this study could be the interaction effects observed during data analysis. They were not considered during data collection. It was thus difficult to answer whether these interactions affected adherence to HAART in this investigation. Another limitation could be that the data were taken at one treatment site. Considering two or more sites in the investigation would have made a difference in giving additional information about the findings. Further study on adherence to HARRT and its determinants with multiple adherences to HAART measurements is thus recommended. Moreover, the study design for the current investigation shows that adherence to HAART was measured using pill count, but some of the patients could discard the unused pills 
and inflate adherence performance. This needs further investigation and can be considered as potential research gap for future investigators.

\section{The way forward}

Due attention should be given to address the specific needs of different groups of patients. Patients with poor adherence to HAART in this longterm treatment program were at risk and interventions should target these groups. Patients should initiate HAART early enough to reduce mortality, morbidity and HIV transmission (Adams and Luguterah, 2013; Asfaw et al., 2015). Single intervention strategy cannot improve risks of patients with non-adherent to HAART. Many studies underscore that successful attempts to improve patients' adherence depends on a set of key factors. These include extended consultation time for male patients and for patients who come from rural areas. In consultation, there should be explanation and reinforcement of medication instructions and the use of reminder calls and alarms. Indeed, measuring adherence to HAART using lag-variables with other covariates encourage those patients who were non-adherent in the previous visits, which contributes to the longevity of their life through the therapy. The strength of this study is that it suggests the effect of lag-variables and their interaction with certain covariates which is advantageous for future researchers to work on the area. In conclusion, during the conduct of this research, certain groups that require special attention were identified, a finding that helps intervene in HAART activities and improve survival.

\section{ACKNOWLEDGEMENTS}

We acknowledge the Amhara Region Health Research \& Laboratory Center at Felege Hiwot Teaching and Specialized Hospital, Ethiopia, for supplying the data for this research.

Competing interests: No individual or institution has funded this research, and therefore, there is no conflict of financial interest between authors or between authors and institutions. 
Consent for publication: The data supporting these findings were kept confidential to protect the identity of participants and respect their privacy. Consent note from participants was not obtained because secondary data was used.

\section{REFERENCES}

Adams, $\mathrm{M}$ and Luguterah, A. (2013a). Longitudinal analysis of change in CD4+ cell counts of HIV-1 patients on antiretroviral therapy (ART) in the Builsa district hospital. European Scientific Journal 9:47-52.

Adams, $\mathrm{M}$ and Luguterah, A. (2013b). Longitudinal analysis of change in CD4+ cell counts of HIV-1 patients on antiretroviral therapy (ART) in the Builsa district hospital. European Scientific Journal 9:38.

Agresti, A and Kateri, M. (2011). Categorical data analysis, international encylcopedia of statistical Science (pp.206-208), Springer, Berlin Heidalburg.

Anlay, D.Z., Alemayehu, Z.A and Dachew, B.A. (2016). Rate of initial highly active anti-retroviral therapy regimen change and its predictors among adult HIV patients at University of Gondar Referral Hospital, Northwest Ethiopia: a retrospective follow up study. AIDS Research and Therapy 13: 1.

Asfaw, A., Ali, D., Eticha, T., Alemayehu, A., Alemayehu, M and Kindeya, F. (2015a). $\mathrm{Cd} 4$ cell count trends after commencement of antiretroviral therapy among HIVinfected patients in Tigray, Northern Ethiopia: a retrospective cross-sectional study. Plos one 10:35-39.

Asfaw, M., Wondaferash, M., Taha, M and Dube, L. (2015b). Prevalence of undernutrition and associated factors among children aged between six to fifty nine months in Bule Hora district, South Ethiopia. BMC Public Health 15: 41-47.

Atkinson, M.J and Petrozzino, J.J. (2009). An evidence-based review of treatmentrelated determinants of patients' nonadherence to HIV medications. AIDS Patient Care and Sexually Transmitted Diseases 23: 903-914.

AVERT (2016). Voluntary medical male circumcision for HIV prevention in 14 priority countries in East and Southern Africa. Nature 345: 125.

Chahkandi, M and Ganjali, M. (2009). On some lifetime distributions with decreasing failure rate. Computational Statistics \& Data Analysis 53: 4433-4440.

Connolly, S. J., Eikelboom, J., Joyner, C., Diener, H.-C., Hart, R., Golitsyn, S., Flaker, G., Avezum, A., Hohnloser, S.H and Diaz, R. (2011). Apixaban in patients with atrial fibrillation. New England Journal of Medicine 364: 806-817.

Ehret, G.B., Munroe, P.B., Rice, K.M., Bochud, M., Johnson, A.D., Chasman, D.I., Smith, A.V., Tobin, M.D., Verwoert, G.C and Hwang, S.J. (2011). Genetic variants in novel pathways influence blood pressure and cardiovascular disease risk. Nature 478: 103 . 
Jamison, D.T., Breman, J.G., Measham, A.R., Alleyne, G., Claeson, M and Evans, D.B (eds). (2006). Disease control priorities in developing countries, Washington, D.C.: World Bank.

Little, R.J and Rubin, D.B. (2014). Statistical analysis with missing data. AIDS and Behavior 12: 37.

Luguterah, A and Adams, M. (2013). Growth dynamics of CD4 cells in HIV-1 patients on antiretroviral therapy (ART) at the Builsa district hospital in Ghana. American Journal of Medical and Biological Research 1: 138-144.

Maqutu, D., Zewotir, T., North, D., Naidoo, K and Grobler, A. (2011). Determinants of optimal adherence over time to antiretroviral therapy amongst HIV positive adults in South Africa: a longitudinal study. AIDS and Behavior 15: 1465-1474.

McLain, A.C., Sundaram, R., Louis, B and Germaine, M. (2015). Joint analysis of longitudinal and survival data measured on nested timescales by using shared parameter models: an application to fecundity data. Journal of the Royal Statistical Society: Series C (Applied Statistics) 64: 339-357.

Montarroyos, U.R., Miranda-Filho, D.B., César, C.C., Souza, W.V., Lacerda, H.R., Albuquerque, M.D.F.P.M., Aguiar, M.F and De Alencar Ximenes, R.A. (2014). Factors related to changes in CD4+ T-cell counts over time in patients living with HIV/AIDS: a multilevel analysis. Plos One 9: e84276.

Moore, R.D. (2011). Epidemiology of HIV infection in the United States: implications for linkage to care. Clinical Infectious Diseases 52: S208-S213.

Noorian, S and Ganjali, M. (2012). Bayesian analysis of transition model for longitudinal ordinal response data: application to Insomnia data. International Journal of Statistics in Medical Research 1: 148-161.

Seyoum, A., Ndlovu, P and Zewotir, T. (2016). Quasi-Poisson versus negative binomial regression models in identifying factors affecting initial CD4 cell count change due to antiretroviral therapy administered to HIV-positive adults in North-West Ethiopia (Amhara region). AIDS Research and Therapy 13: 36.

Seyoum, A and Temesgen, Z. (2017). Joint longitudinal data analysis in detecting determinants of CD4 cell count change and adherence to highly active antiretroviral therapy at Felege Hiwot Teaching and Specialized Hospital, North-west Ethiopia (Amhara Region). AIDS Research and Therapy 14: 14.

Seyoum, A and Zewotir, T. (2016). Quasi-Poisson versus negative binomial regression models in identifying factors affecting initial CD4 cell count change due to antiretroviral therapy administered to HIV-positive adults in North-West Ethiopia (Amhara region). AIDS Research and Therapy 13: 36.

Seyoum, D., Degryse, J.M., Kifle, Y.G., Taye, A., Tadesse, M., Birlie, B., Banbeta, A., Rosas-Aguirre, A., Duchateau, L and Speybroeck, N. (2017). Risk Factors for Mortality among Adult HIV/AIDS Patients Following Antiretroviral Therapy in Southwestern Ethiopia: An Assessment through Survival Models. International Journal of Environmental Research and Public Health 14: 296.

Sisay, M.M., Ayele, T.A., Gelaw, Y.A., Tsegaye, A.T., Gelaye, K.A and Melak, M.F. (2018). Incidence and risk factors of first-line antiretroviral treatment failure among 
human immunodeficiency virus-infected children in Amhara regional state, Ethiopia: a retrospective follow-up study. BMJ Open 8: e019181.

Skhosana, N.L., Struthers, H., Gray, G.E and Mcintyre, J.A. (2006). HIV disclosure and other factors that impact on adherence to antiretroviral therapy: the case of Soweto, South Africa. African Journal of AIDS Research 5: 17-26.

Tegegne, A.S and Zewotir, T. 2018a. Determinants of CD4 cell count change and timeto default from HAART; a comparison of separate and joint models. BMC Infectious Diseases 18: 197.

Tegegne, A.S and Zewotir, T. 2018b. Factors affecting first month adherence due to antiretroviral therapy among HIV-positive adults at Felege Hiwot Teaching and Specialized Hospital, north-western Ethiopia; a prospective study. BMC infectious Diseases 18: 83. 